1. MBBS, FCPS (Medicine)

Senior Registrar Medicine

ABWA Medical College, Faisalabad.

2. MBBS, MRCP (UK)

Assistant Professor Medicine Independent Medical College/

Hospital, Faisalabad.

3. MBBS, MRCP (UK)

Assistant Professor Medicine

Aziz Fatima Medical and Dental

College/Hospital, Faisalabad.

4. MBBS, MRCP

Senior Registrar Medicine

Madina Teaching Hospital,

The University of Faisalabad.

5. MBBS FCPS

Assistant Professor Medicine Punjab Medical College (FMU),

Allied Hospital, Faisalabad.

6. MBBS

Demonstrator

The University of Lahore, Lahore.

Correspondence Address:

Dr. Muhammad Asif Javed

Department of Medicine

ABWA Medical College, Faisalabad.

drasifjaved61@gmail.com

Article received on:

06/11/2019

Accepted for publication:

$22 / 04 / 2020$

\section{COMPARISON OF EFFICACY OF DULOXETINE WITH AMITRIPTYLINE IN TERMS OF REDUCTION IN FREQUENCY OF PAIN IN THE PATIENTS OF DIABETIC NEUROPATHY.}

\begin{abstract}
Muhammad Asif Javed ', Muhammad Absar Alam², Atif Maqsood ${ }^{3}$, Amna Azher', Muhammad Arif5, Anoosh Qayyum ${ }^{6}$

ABSTRACT... Objectives: To compare the efficacy of Duloxetine with Amitriptyline in Terms of Reduction in Frequency of Pain in The Management of Patients of Diabetic Neuropathy. Study Design: Randomized Control Trial. Setting: Medical OPD of ABWA Medical College Hospital Faisalabad. Period: Six Months from 01-01-2019 to 30-06-2019. Material \& Methods: A total of 200 cases (100 in each group) between the age 20-65 years of any gender, $\geq 5$ years history of diabetes, symptoms of peripheral neuropathy for at least six months, having $\mathrm{HbA} 1 \mathrm{c}$ $>7.5 \%$ were included. Two groups were formed Group A was given 60mg Duloxetine each day and Group B was given 75mg amitriptyline in a single dose. After 3 weeks, an additional three weeks supply of medication was dispensed and patient were scheduled to return at week 6 for the final evaluation that recorded by me in terms of reduction in pain score and also assessed for $50 \%$ reduction in pain score from base line that was labeled as reduced. Results: $62 \%(n=62)$ in Group-A and 35\% $(n=35)$ in Group-B were treated effectively, which shows a significant difference between the two groups. Conclusion: The duloxetine was more effective than amitriptyline in terms of reduction of pain in diabetic neuropathy.
\end{abstract}

Key words: $\quad$ Amitriptyline, Efficacy, Duloxetine, Diabetic Neuropathy, Management.

Article Citation: Javed MA, Alam MA, Maqsood A, Azher A, Arif M, Qayyum A. Comparison of efficacy of duloxetine with amitriptyline in terms of reduction in frequency of pain in the patients of diabetic neuropathy. Professional Med J 2020; 27(9):1891-1894. DOI: 10.29309/TPMJ/2020.27.09.4289

\section{INTRODUCTION}

Hyperglucemia (Diabetes Mellitus) is a metabolic disorder ${ }^{1}$, presence of signs and symptoms of peripheral nerve dysfunction in diabetics like pain with any of following numbness, tingling and paraesthesia in patients with diagnosed diabetes for more than 5 years is known as diabetic peripheral neuropathy(DPN). ${ }^{2}$ Commonly, quality of is affected in these cases. ${ }^{3}$ It is recorded in $47 \%$ of the subjects with diabetes mellitus when diagnosed with the help of nerve conduction testing. ${ }^{4}$ Painful diabetic peripheral neuropathy (PDPN) in $25 \%$ of the diabetics. ${ }^{5}$ The symptoms range from mild dysesthesias to severe unremitting pain which may potentially affect the quality of life. ${ }^{6}$ Various factors are involved in pathogenesis of DPN including hyperglycemia, dyslipidemia, growth factor deficiencies, oxidative and nitrosative stress, autoimmune damage to nerve fibers and microvascular insufficiency. ${ }^{7-9}$ The management of painful diabetic peripheral neuropathy is difficult and these cases require more attention as compared to those with other types of diabetic neuropathies. ${ }^{10-12}$

Commonly used classes of agents for the management of diabetic peripheral neuropathic pain are anticonvulsants, antidepressants, serotonin norepinephrine reuptake inhibitors and topical medications. ${ }^{13-14}$ Now a days first line therapies include TCA, SNRI, or anticonvulsant's considering the fact of cost and co-morbidities. ${ }^{15}$ TCA like amitriptylinis proposed as a first line therapy for neuropathic pain. The mechanism action is considered to be inhibition of norepinephrine and / or serotonin reuptake within the central nervous system. However, other possible mechanisms include sodium channel effect, alpha-adrenergic blockage, and NMDAreceptor for antagonism. ${ }^{16}$

On the other hand, Duloxetine hydrochloride and 
pregabalin are also used for the relief of pain in diabetic peripheral neuropathy. ${ }^{17}$ Blockage of reuptake of serotonin and norepinepinephrine is the mechanism of this drug. ${ }^{18}$

This study was planned to explore the clinical improvement in patients with DPN on duloxetine as compared to amitriptyline. That will help us to modify the treatment of this common disorder resulting in better patient care.

\section{MATERIAL \& METHODS}

The study was conducted at Medical OPD of ABWA Medical College Hospital Faisalabad. A total of 200 cases (100 in each group) between the age 20-65 years of any gender, $\geq 5$ years history of diabetes, symptoms of peripheral neuropathy for at least six months, having $\mathrm{HbA1c}$ $>7.5 \%$ were included while those with co-existing other causes of peripheral neuropathy (porphyria, chronic renal failure, amyloidosis, leprosy, hypothyroidism), pregnant and lactating women and use of Duloxetine or amitriptyline in previous three months were excluded from the study. Randomization was done by computer generated random number table, to allocate patients to either group A (Duloxetine group) or group B (Amitriptyline group). Patients were instructed to take study medication in the morning, with a glass of water for up to 6 weeks. Group A was given 60mg Duloxetine each day and Group B was given $75 \mathrm{mg}$ amitriptyline in a single dose.

Baseline pain was recorded on VAS. Diary card was provided to all patients at the baseline visit. Each morning during the 1st 3 weeks, patients would be instructed to record the severity of the symptoms in term of reduction in pain score recorded by visual analogue scale. After 3 weeks, an additional three weeks supply of medication was dispensed and patient were scheduled to return at week 6 for the final evaluation that recorded by me in terms of reduction in pain score and also assessed for $50 \%$ reduction in pain score from base line that was labeled as reduced. Patients were followed up by keeping telephonic contacts of patients.

\section{RESULTS}

In this study, out of 200 cases (100 in each group) $21 \%(n=21)$ in Group-A and $17 \%(n=17)$ in Group-B were between $20-40$ years of age while $79 \%(n=79)$ in Group-A and $83 \%(n=83)$ in Group-B were between 41-65 years of age, mean+sd was calculated as $47.08+11.43$ and $48.37+10.83$ respectively, $56 \%(n=56)$ in Group-A and $49 \%(n=49)$ in Group-B were male while $44 \%(n=44)$ in Group-a and $51 \%(n=51)$ in Group-B were females, comparison of efficacy in both groups was done which shows that $62 \%(n=62)$ in Group-A and $35 \%(n=35)$ in Group-B were treated effectively, which shows a significant difference between the two groups.

\begin{tabular}{|c|c|c|c|c|}
\hline \multirow{2}{*}{ Efficacy } & \multicolumn{2}{|c|}{$\begin{array}{l}\text { Group-A } \\
(n=100)\end{array}$} & \multicolumn{2}{|c|}{$\begin{array}{r}\text { Group-B } \\
(n=100)\end{array}$} \\
\hline & $\begin{array}{c}\text { No. of } \\
\text { Patients }\end{array}$ & $\%$ & $\begin{array}{l}\text { No. of } \\
\text { Patients }\end{array}$ & $\%$ \\
\hline Yes & 62 & 62 & 35 & 35 \\
\hline No & 38 & 38 & 65 & 65 \\
\hline Total & 100 & 100 & 100 & 100 \\
\hline \multicolumn{5}{|c|}{$\begin{array}{l}\text { Table-I. Comparison of efficacy in both groups } \\
\qquad \begin{array}{c}(n=200) \\
\text { P value }=0.000\end{array}\end{array}$} \\
\hline
\end{tabular}

\section{DISCUSSION}

We planned this study to explore the clinical improvement in patients with DPN on duloxetine as compared to amitriptyline which may help us to modify the treatment of this common disorder resulting in better patient care.

In our study, out of 200 cases (100 in each group) $21 \%(n=21)$ in Group-A and $17 \%(n=17)$ in Group-B were between 20-40 years of age while $79 \%(n=79)$ in Group-A and $83 \%(n=83)$ in Group-B were between 41-65 years of age, mean+sd was calculated as $47.08+11.43$ and $48.37+10.83$ respectively, $56 \%(n=56)$ in Group-A and $49 \%(n=49)$ in Group-B were male while $44 \%(n=44)$ in Group-a and $51 \%(n=51)$ in Group-B were females, comparison of efficacy in both groups was done which shows that $62 \%(n=62)$ in Group-A and $35 \%(n=35)$ in Group-B were treated effectively, which shows a significant difference between the two groups. 
Shahid S and others ${ }^{19}$ support our results. We found similar findings in a previous study showing $59 \%$ of the patients treated with duloxetine having reduction in pain. ${ }^{20}$ Another study $41.4 \%$ of patients treated with amitriptyline showed reduction in pain. ${ }^{21}$

Duloxetine is reported to be well tolerated in the trials, with fewer withdrawals due to adverse events with $60 \mathrm{mg}$ than with $120 \mathrm{mg}$. Most adverse events were reported to be mild or moderate, with nausea, somnolence, constipation, decreased appetite and dry mouth frequently mentioned. In stress incontinence duloxetine affects the resting tone and contraction of the urethral striated sphincter muscle. It might be expected to cause symptoms of urinary hesitancy in patients without incontinence, but urinary problems were not reported in any of these trials, or in trials of duloxetine in depression. ${ }^{22-23}$

The results of our study clearly justifies the hypothesis of the study that "Duloxetine is more effective in reducing the pain in patients of diabetic neuropathy as compared to amitriptyline" is justified. However, being the limitation of the study we did not analyze the side effects and withdrawals of the treatment in our study, which is recommended in further trials.

\section{CONCLUSION}

It is concluded that the efficacy of duloxetine as compare to the amitriptyline in terms of reduction in frequency of pain in the management of patients of diabetic neuropathy is significantly higher.

\section{Copyright@ 22 Apr, 2020.}

\section{REFERENCES}

1. Akram N, Butt A, Waheed K, Ahmad A. Peripheral neuropathy in newly diagnosed cases of type II diabetes mellitus. Pak J Neurol Surg 2019; 23:234-8.

2. Tesfaye S. Assessment and management of painful diabetic peripheral neuropathy. In: Tesfaye S, Boultan A, editors. Diabetic neuropathy New York: Oxford University Press; 2009; 37-52.

3. Taj S, Anwar K, Sajjad AG. Awareness about peripheral diabetic neuropathy among physical therapists in twin cities. JSTMU 2019; 2(2):28-32.
4. Ormseth MJ, Scholz BA, Boomershine CS. Duloxetine in the management of diabetic peripheral neuropathic pain. Patient prefer Adherence. 2011; 5:343-56.

5. Snyder MJ, Gibbs LM, Lindsay TJ: Treating painful diabetic peripheral neuropathy: An update. Am Fam Physician 2016; 94:227-34.

6. Devi P, Madhu K, Ganapathy B, Sarma GRK, John L, Kulkarine C. Evaluation of efficacy and safety of gabapentin, duloxetine, and pregabalen in patients with painful diabetic peripheral neuropathy. Indian J Pharmacol. 2012; 44:51-6.

7. Vinik A. The Approach to the management of the patient with neuropathic pain. J Clin Endocrinol Metab 2010; 95:4802-1.

8. Yang $\mathrm{CP}, \mathrm{LiCl}$, Liu CS, et al. Variability of fasting plasma glucose increased risks of diabetic polyneuropathy in T2DM. Neurology 2017; 88:944.

9. Jaiswal M, Divers J, Dabelea D, et al. Prevalence of and risk factors for diabetic peripheral neuropathy in youth with type 1 and type 2 diabetes: SEARCH for diabetes in youth study. Diabetes Care 2017; 40:1226.

10. Snyder MJ, Gibbs LM. Treating painful diabetic peripheral neuropathy: An Update. Am Fam Physician. 2016 Aug 1; 94(3):227-34.

11. Vinik Al, Caseuine CM. Guidelines in the management of diabetic nerve pain: Clinical utility of pregabalin. Diabetic nerve pain; Clinical utility of pregabalin. Diabetes Metab Syndr Obes. 2013; 6:57-8.

12. Khdour MR. Treatment of diabetic peripheral neuropathy: A review. Journal of Pharmacy and Pharmacology 2020; doi: doi: 10.1111/jphp.13241.

13. Iyer S, Tanenberg RJ. Pharmacologic management of diabetic peripheral neuropathic pain. Expert Opinion Pharmacother 2016; 14:(13):1-11.

14. Lindsay TJ, Rodgers BC, Sarath V, Hethinger K. Treating diabetic peripheral neuropathic pain. Am Fan Physician. 2010; 82:151-8.

15. Tesfaye S. Advances in the management of diabetic peripheral neuropathy. CurrOpin Support Palliat Care. 2009; 3:136-43.

16. Zilliox L, Russell JW. Treatment of diabetic sensory polyneuropathy. Curr Treat Options Neurol 2011; 13:143-59.

17. Zillox L, Russel JW. Maintaining efficacy in the treatment of diabetic peripheral neuropathic pain: Role of duloxetine. Diabetes Metab Synde Obes. 2010; 3:7-17. 
18. Wright $A$, Luedtke KE, Van Den Berg C. Duloxetine in the treatment of chronic pain due to fibromyalgia and diabetic neuropathy. J Pain Res. 2011; 4:1-10.

19. Shahid W, Kumar R, Shaikh A, et al. Comparison of the efficacy of duloxetine and pregabalin in pain relief associated with diabetic neuropathy. Cureus 2019; 11(7): e5293. doi:10.7759/cureus.5293.

20. Kour H. Hota D, Bhansali A, Dutta P, Bansal D, Chakrabarti A. A comparative evaluation of amitriptyline and duloxetine in painful diabetic neuropathy. Diabetes Care 2011; 34:818-22.
21. Shabir B, Shafi F, Mahboob F. Amitriptyline Vspregabalin in painful diabetic neuropathy: A randomized placebo-based study. Pak J Med Health Sci [Internet]. 2011 Oct-Dec [cited 2011]; 5(4):(about 4p).

22. Perahia DG, Kajdasz DK, Walker DJ, Raskin J, Tylee A. Duloxetine $60 \mathrm{mg}$ once daily in the treatment of milder major depressive disorder. Int J Clin Pract 2006; 60:613-20.

23. Wise TN, Wiltse CG, losifescu DV, Sheridan M, Xu JY, Raskin J. The safety and tolerability of duloxetine in depressed elderly patients with and without medical comorbidity. Int J Clin Pract 2007; 61:1283-93.

\begin{tabular}{|c|l|l|l|}
\hline \multicolumn{3}{|c|}{ AUTHORSHIP AND CONTRIBUTION DECLARATION } \\
\hline Sr. \# & \multicolumn{1}{|c|}{ Author(s) Full Name } & Contribution to the paper & Author(s) Signature \\
\hline 1 & Muhammad Asif Javed & 1st Author \\
\hline 2 & Muhammad Absar Alam & 2nd Author \\
\hline 3 & Atif Maqsood & 3rd Author \\
\hline 4 & Amna Azher & 4th Author \\
\hline 6 & Anoosh Qayyum & 5th Author
\end{tabular}

